\title{
UNA INCURSIÓN EN LOS ORÍGENES. LA INSERCIÓN DE RAMÓN DE LA SAGRA EN LA SOCIOLOGÍA ESPAÑOLA
}

\section{AN INROAD INTO THE ORIGINS. RAMON DE LA SAGRA'S INSERTION INTO SPANISH SOCIOLOGY}

M. Carmen Rodríguez Rodríguez Universidad de A Coruña. España/Spain carmen.rodriguez2@udc.es

Recibido/Received: 15/04/2015

Modificado/Modified: 04/09/2015

Aceptado/Accepted: 18/09/2015

\section{RESUMEN}

Este texto recoge el debate sobre el momento inaugural de la Sociología española. Se plantea el problema de los inicios de la disciplina, realizando un recorrido histórico que revisa el estado de la cuestión, prestando atención a una figura en particular, la de Ramón de la Sagra. A través de una profunda revisión bibliográfica, se perfila, en palabras de los investigadores, la importancia de este autor en los orígenes de estos estudios en España.

\section{PALABRAS CLAVE}

Pionero, precursor, Ramón de la Sagra, Sociología española.

\section{SUMARIO}

1. Introducción. 2. Ramón de la Sagra y la Sociología de su época. 2.1. Sociología y sociología. 2.2. Los inicios de la Sociología española. 2.3. Ramón de la Sagra en la historia de la disciplina. 3. Conclusiones. Bibliografía.

\section{ABSTRACT}

This paper raises the question about the birth of the Spanish Sociology. It introduces the issue about the beginning of such Discipline through an historical journey that reviews the status of the matter paying special attention to Ramon de la Sagra's figure. Going through a deep bibliographic research it is outlined, quoting the experts, the author's importance at the opening stage of the Spanish Sociology.

\section{KEYWORDS}

Pioneer, forerunner, Ramón de la Sagra, Spanish Sociology.

\section{CONTENTS}

1. Introduction. 2. Ramón de la Sagra and the Sociology of his time. 2.1. Sociology and sociology. 2.2. The beginning of the Spanish Sociology. 2.3. Ramón de la Sagra in the discipline's history. 3. Conclusion. References. 


\section{INTRODUCCIÓN}

Es éste un artículo aproximativo, de iniciación, el necesario prólogo al estudio de una figura singular en la Sociología española, la de Ramón de la Sagra (A Coruña, 1798/Neuchâtel, 1871).

El carácter de este autor como uno de los pioneros en este ámbito, ha sido frecuentemente pasado por alto. Por ello, el objetivo de estos apuntes es el de recordarlo y situarlo en la que creemos es su justa posición dentro de la Historia de la Sociología dentro de nuestro país.

Para alcanzar este propósito, dado que no es posible repasar en estas breves líneas en toda su extensión sus logros y su producción, nos limitaremos a situar al autor en la Sociología de su época, contextualizándolo en una etapa inicial, precursora, que necesariamente se instala en territorios limítrofes. Mediante una intensa búsqueda bibliográfica (que forma parte de una investigación de mayor envergadura), observaremos el reconocimiento que su figura como sociólogo encuentra en los autores que intentan reconstruir los orígenes de la disciplina en el ámbito español. Más que un estudio en profundidad de su figura, lo que pretendemos aquí es reconocer el terreno donde germina y analizar los ecos que ésta produce.

Nos proponemos, pues, destacar la figura de Ramón de la Sagra como pionero de la Sociología española y para ello trataremos de contextualizar el origen de la disciplina sociológica para ver cómo se inserta Ramón de la Sagra en este campo en nuestro país. En un primer apartado subrayamos la pertinencia de volver a reconsiderar la figura de Ramón de la Sagra como iniciador. A continuación ofrecemos unas breves consideraciones sobre los comienzos de la Sociología, para pasar a hablar del arranque de la disciplina en España visto desde la perspectiva de los investigadores. Finalmente, también desde esta óptica, recopilamos cuál es la opinión de los historiadores de la Sociología española sobre la inserción de Ramón de la Sagra dentro de la materia.

\section{RAMÓN DE LA SAGRA Y LA SOCIOLOGÍA DE SU ÉPOCA}

Dado el creciente interés que despierta la Sociología española, sobre todo la iniciadora, resulta interesante retrotraernos a un período (el de nuestro personaje) en el que no podemos hablar de figuras que se reconocen como netamente sociológicas, pero que serán las que asienten las bases de lo que en un futuro será esta disciplina. Y aquí hay que subrayar la posición pionera que Ramón de la Sagra ocupa dentro de la Sociología en España, una ciencia que a principios del siglo XIX aún estaba en ciernes. Teniendo todo esto en cuenta, consideraremos aquí a nuestro autor como precursor o presociólogo en el sentido estricto, pues es anterior a la institucionalización de la Sociología, pero sociólogo en sentido amplio, pues presumimos que ya hace sociología. Es más, incluso podemos afirmar que es un iniciador de la Sociología moderna en España.

Pero antes de rastrear la presencia de R. de la Sagra en la Sociología, nos parece necesario constatar su ausencia. A la hora de acercarnos a la figura de este escritor español en su faceta más sociológica, nos encontramos ante el implacable muro que construye el olvido. Llama la atención que sea una de las figuras más ignoradas por la Sociología española, a pesar de su carácter pionero, su notable producción y sus aportaciones al movimiento reformista en la España del siglo XIX.

Teniendo este hecho en cuenta, hemos de precisar las dimensiones que alcanza este olvido. Respecto a esta cuestión, las opiniones están enfrentadas, pues, si algunos de sus 
biógrafos aseveran que la ignorancia (voluntaria o involuntaria) de su figura es prácticamente total, otros consideran que esta afirmación es exagerada y que, realmente, es un personaje estudiado y revisado. Ante estos dos extremos, nos inclinamos por suscribir la primera tesis, pues, si bien es verdad que R. de la Sagra es una figura que aparece de una forma recurrente en los manuales sobre Historia de la Sociología española, hemos de admitir que su presencia en estos es más bien discreta y puntual, sobre todo si consideramos el peso real de sus aportaciones. Paradójicamente, es en obras que analizan su producción no sociológica, en donde encontramos los estudios más profundos sobre este autor. Además, se suele cometer el error de estudiarlo de una manera superficial o parcial, centrándose sólo en una etapa pero generalizándola a su obra completa. Un ejemplo de ello es el recurrente estudio sesgado del que es objeto R. de la Sagra, en el que no se duda en tomar la parte por el todo y reivindicar su carácter conservador apoyándose en la producción de su última etapa (una, y no precisamente la más destacada intelectualmente, entre varias).

Para redimir en parte esta carencia, se puede reconocer a R. de la Sagra como sociólogo desde una doble perspectiva: viendo qué sociología hace (al analizar de una forma directa su trabajo, labor que dejamos para otra ocasión) e identificando su posición dentro de la Historia de la Sociología española (comprobando mediante un ejercicio de reflexividad en qué momento histórico lo podemos situar, qué es lo que sobre él opinan los estudiosos de la Sociología). Es a esta segunda cuestión a la que dedicaremos el presente artículo.

\subsection{Sociología y sociología}

Al mencionar el sentido estricto y el amplio que tiene la palabra Sociología (y el término sociólogo), nos topamos aquí con el problema de su definición (y, por tanto, de sus límites), materia en la que nos resistimos a profundizar teniendo como tenemos complejos textos sobre el tema. Por ello, de aquí en adelante hacemos una diferenciación entre el término Sociología, referido a la sociología moderna o científica, y sociología, utilizado en un sentido más amplio con el significado de pensamiento o teoría social.

Simplificando el debate, la cuestión sobre qué es Sociología desemboca en una disputa por situar su origen y en la pregunta de si es posible encontrarlo antes del nacimiento de la Ciencia moderna, antes de la Revolución Industrial o antes de su institucionalización. Esto significa que la fecha de aparición de la Sociología en el escenario intelectual se presente como incierta (por la imprecisión en su definición y al no haber unanimidad sobre su momento inaugural) y se relativice (su implantación depende de cada país y además se considera movediza, al estar sometida a modas intelectuales y al variar los conceptos sus contenidos a lo largo del tiempo, construyéndose con el pasar de los años). La noción sigue así los dictados de un "efecto Penélope" que, "lleva a hacer y deshacer teorías y métodos en función de usos determinados por valores culturales, políticos y económicos sujetos al devenir histórico" (Sarabia, 2001:17).

Tampoco es ajena a la definición de la materia la mirada del experto, en la que: "las estructuras sociales, los estilos de vida, y las posiciones de los sociólogos en el campo intelectual y en el campo social, contribuyen a conformar específicas estructuras mentales. Estos agentes sociales comparten en ocasiones valores, puntos de vista, conceptos y representaciones, formas de aproximación a la realidad, clasifican los hechos sociales en función de determinadas disposiciones mentales" (Álvarez-Uría et al., 2000:25-26).

Son disposiciones a veces reconocidas por ellos de forma explícita, y otras no, como las background assumptions de A. Gouldner o el concepto de habitus de P. Bourdieu. En definitiva, lo que sacamos en claro de esta búsqueda de identidad (de posicionamiento dentro 
de la sociedad, al fin y al cabo), de esta autorreflexión, es su dificultad: "Somos conscientes de que esta tarea no es fácil si tenemos en cuenta además el juicio generalizado que se ha instalado en la propia comunidad sociológica. En ella es frecuente que se considere nuestra actividad como el desempeño de una ciencia en "recurrente crisis", debido a la situación de incertidumbre que suele acompañar a los resultados de la práctica sociológica. Esta actitud escéptica cuando no ecléctica del propio sociólogo sobre su actividad, hace que la opinión social recele y en ocasiones cuestione el significado y el alcance del estatuto logrado por la sociología. Tal desconfianza, así como el cambiante halo que se le atribuye a la disciplina, puede atribuirse, entre otras causas, a la falta de atención que se le ha prestado hasta ahora a la tarea sociológica global realizada y a su evolución" (Morente, 2000:272).

Dado este panorama, donde domina la evidente variabilidad de la disciplina sociológica, nos remitimos puntualmente a la lúcida tesis de A. Ribes (2005) al recordar la necesidad de adoptar un enfoque teórico histórico-práctico e inclusivo en su estudio, que preste atención al reconocimiento de diferencias, a los márgenes de la sociología y al cambio.

Más que insistir sobre la ruptura radical (el establecimiento de un antes y un después) que conduce a la fragmentación de opiniones, nos interesa señalar el elemento común que uniría las distintas perspectivas, la existencia de un "enfoque sociológico", en consonancia con la "imaginación sociológica" de C. W. Mills, una forma de mirar determinada en la sociología que otorgue cierto carácter distintivo al análisis sobre lo social (que le permita definirse a sí misma, y también con respecto a las demás áreas afines). Es la búsqueda de la coherencia en la diversidad, el intento de reunir bajo el epígrafe "Sociología" a la versión más ortodoxa de esta materia con la llamada "sociología difusa". Esta última es: "una forma de hacer sociología, es decir, de aplicar la tradición sociológica a cualquier realidad social, pero expresar los resultados de una manera poco académica; mediante ensayos o artículos de prensa, por ejemplo. (...). En muchas ocasiones este tipo de trabajos son considerados como la obra menor de un autor; sin embargo, esta manera de considerar a este tipo ideal de "sociología difusa" no tiene en cuenta que en algunos contextos histórico-sociales ciertos autores han pretendido llegar de una manera más clara a la sociedad sobre la que escribían (...). En estos trabajos se pretende sugerir más que demostrar, y las citas se reducen o incluso se omiten, aunque el peso de las ideas de otros autores se pueda observar con relativa facilidad" (Ribes, 2005:73-74).

Aquí podríamos incluir, por ejemplo, los diarios de viaje de R. de la Sagra, pues el género literario "diario de viaje", como ya indicaba Gómez Arboleya (1990), constituye una forma de conocimiento social que se sitúa entre el conocimiento más divulgador y popular de la ciencia y la etnosociología.

Atendiendo a la existencia de ese enfoque sociológico, podemos constatar que existe una tradición anterior que alimenta el modo de pensar sociológico (Aron, 1970), anterior al proceso de institucionalización oficial de la Sociología, proceso cuyo comienzo podemos situar en el momento en que se la denomina y que culminará en el siglo XX con su constitución como disciplina perfectamente definida. Será Auguste Comte en 1838, en la lección 47 de su Cours de philosophie positive, quien utilice por primera vez esta palabra para bautizar esta "nueva ciencia" (aunque había sido acuñada mucho antes, en 1824).

Siendo flexibles, podemos rastrear el estudio de la sociedad por parte del hombre en los albores de la humanidad, desde la fillosofía griega. Aquí nos gustaría recordar la propuesta de Giner (2004), en la que realiza un remonte histórico (siguiendo la "lógica expansiva de la indagación científica") sobre la ciencia de la sociedad. Como señala Giner: "El esfuerzo por entender y explicar racional y analíticamente la condición humana y la sociedad formada por los seres humanos prescindiendo de invocaciones a fuerzas sobrenaturales se la debemos a la 
civilización helena. (...) El cultivo del conocimiento secular en la Antigüedad llevó a algunos pensadores helenos a intentar explicar la vida social mediante criterios que hoy pertenecen plenamente a las ciencias sociales" (Giner, 2004:18).

Este autor también destaca el papel fundamental que tiene la revolución científica que comienza con el Renacimiento (s. XV) y culmina con la Ilustración (s. XVIII), pero puntualiza que "Lo sucedido en los tiempos modernos en este campo, sin embargo, se halla en profunda deuda con aquellas épocas anteriores, desde la Grecia clásica hasta el fin de la Edad Media, en que se fraguó tal tradición, aunque de forma desigual o intermitente" (Giner, 2004:17). Sigue así la línea histórica para rendir tributo a las aportaciones romanas (sobre todo, las de sus historiadores) y a los teóricos sociales medievales, como Tomás Moro con su Utopía, Maquiavelo con El príncipe y los Discursos o Juan Luis Vives con el Socorro de los pobres. Será en el Renacimiento cuando aparezca la nueva mentalidad moderna que posibilite los requisitos de toda teoría social seria, es decir, rigurosa, racional, secular y empíricamente orientada. A partir de ahí, se llegaría a la figura de Montesquieu, a quien S. Giner señala como el primer autor cuyo espíritu es plenamente sociológico.

En esta historia del conocimiento del hombre, supondría un punto y aparte, un "acontecimiento anómalo" a destacar, el descubrimiento de un Nuevo Mundo paralelo al Occidental, nuevo por su condición de desconocido, extraño y primigenio. Este choque fundamental, que pronto se incorporaría a la civilización occidental, es señalado por muchos autores como un momento en el que se cambia la perspectiva del conocimiento de la sociedad, sobre todo por la mirada comparativa que provoca. Siendo precisos, el descubrimiento de América se ha de enmarcar en la carrera de los grandes descubrimientos geográficos (recogida en una nutrida literatura de viajes), donde varios autores sitúan los orígenes de la Sociología, pues el inicial viaje de exploración exterior pasará a ser un viaje de exploración interior y de autoconocimiento. El descubrimiento del Nuevo Mundo resultará ser un proceso largo en el tiempo, por lo que dentro de los testimonios que dan cuenta de esta mirada comparativa pueden comprenderse desde las Crónicas de Indias (en donde algunos vislumbran los inicios de la Sociología española), hasta la Democracia en América de A. de Tocqueville.

Como vemos, desde el momento en que se puede distinguir un punto de partida anterior (con personalidades, con temáticas y perspectivas sociológicas previas) a los momentos de corte tradicionales que se sitúan, preferentemente, en el nacimiento del método moderno de conocimiento (con la Ciencia moderna), del objeto de conocimiento (la sociedad industrial plenamente diferenciada de la estamental anterior) o del sujeto de conocimiento (el sociólogo, que estudia una materia determinada y está inscrito en unas instituciones concretas), podemos intuir que parece haber sociología más allá de lo que se denomina la Sociología moderna.

Con esta distinción entre sociología y Sociología, verificamos la existencia de una cesura que afecta a la disciplina, no en cuanto a lo que al "enfoque sociológico" se refiere, sino a su carácter científico. Este momento de inflexión se ha de situar, más que en su institucionalización o en la aparición de la sociedad industrial, en su conversión en ciencia social moderna.

La institucionalización es un proceso de autodefinición y, por ello, se suele situar su inicio con su propia denominación como "Sociología", hecho que para muchos convierte a su autor, A. Comte, en el padre de esta ciencia (Mucchielli, 2000). Pero hay voces disidentes ante la radicalidad de esta paternidad, como R. Aron (1970), quien mitiga este papel al presentar como sociólogos de pleno derecho a figuras cuyo trabajo es anterior a la designación, como 
son H. Saint-Simon o A. de Tocqueville. Este debate nos lleva nuevamente a la cuestión de si existe sociología antes de la Sociología, si se puede estar haciendo sociología antes de saber que se está haciendo Sociología (en nuestra opinión la respuesta es positiva). Otra objeción la plantea I. Sotelo ante la afirmación de A. de Miguel en Sociología o subversión (1972) de que la existencia de la sociología, como saber específico, coincide con su institucionalización (como carrera universitaria y como profesión). I. Sotelo considera esta opinión evasiva ante las exigencias de un análisis en profundidad: "Hace bien De Miguel en amarrarse al criterio institucional -sociología es lo que hacen las instituciones académicas y profesionales reconocidas-, porque fuera de él, tanto en España como allende sus fronteras, reina la más absoluta confusión sobre lo que pueda ser esta disciplina. Enfrentarse con la raíz de esta confusión, es decir, con la cuestionabilidad intrínseca de la sociología como ciencia social específica desde que Comte creó este desafortunado neologismo, sería una ardua tarea que exigiría, por lo menos, una perspectiva metasociológica" (Sotelo, 1973:61).

Sobre la cuestión de que el momento de inflexión se sitúe en la aparición de la sociedad industrial, esta postura ha sido también ampliamente puesta en duda por I. Sotelo. Vuelve a rebatir la tesis básica de A. de Miguel que relaciona la sociedad industrial con la aparición de la sociología (y que justifica la tardía introducción de esta materia en una España poco desarrollada en ese sentido, al no haber una burguesía que la impulsase y que promoviese su institucionalización), I. Sotelo cuestiona esta interrelación directa con el ejemplo contrario: "Si bien España se caracteriza por el "cortocircuito de la modernidad", con enormes dificultades para incorporarse al proceso de industrialización, nadie negará que Inglaterra constituye el modelo mismo de la "modernidad", en donde se inicia la primera industrialización. Con una "revolución burguesa" que se remonta al siglo XVII, ¿qué país podría reunir mejores condiciones para un florecimiento temprano y una pronta institucionalización de la sociología? Sin embargo, "la historia de la sociología británica hasta 1914 -en realidad, hasta 1945 - no es en ningún sentido un relato exitoso"' (Sotelo, 1973:66).

Sin embargo, hay otra forma de entender este supuesto, de una manera menos radical y más contextualizada, que sería la postura de aquellos que ven el origen de la Sociología moderna como una forma de intentar comprender y hallar sentido a la caída del Antiguo Régimen y a la constitución de un nuevo orden a partir de la Revolución industrial y el liberalismo. En esta ruptura que marca la caída del Antiguo Régimen (y la aparición de un nuevo objeto de conocimiento al que hay que dar sentido), es donde se encontraría el fundamento de las orientaciones ideológicas racionales que aparecen como respuesta ante las crisis sociales y que F. Morente, siguiendo a I. Zeitlin e I. Sotelo, resume en las cuatro siguientes: el discurso contrarrevolucionario, el proyecto idealista, la conciencia revolucionaria y la pragmática tecnocrática (Morente, 2000:278). Por otra parte, una situación radicalmente distinta de la anterior, en cierto modo necesita una forma distinta de conocer, que aproveche los nuevos instrumentos de los que se dispone (lo que entroncaría con la aparición del método científico). De este modo, "El conocimiento sociológico surge como necesaria respuesta a las demandas que emergen de un complejo e inédito contexto histórico-social" (Rodríguez, 1999:263). Realmente, el conocimiento científico moderno necesita la existencia de unas bases para su desarrollo, no sólo un método, sino también una sociedad moderna, un sujeto de conocimiento que sea capaz de establecerlo y aplicarlo. Esto se relaciona con la aparición de la burguesía: "La ascensión de la clase burguesa compuesta de individuos en cierto modo desarraigados, que lo debían todo a su esfuerzo, mediante la racionalización de los elementos de su vivir, marca no sólo el triunfo de una mentalidad, sino condiciona los modos de esta mentalidad. Sólo cuando esta clase no sólo dominó sectores de 
la realidad y de la vida social, sino la realidad social europea en cuanto tal, pudo cobrar plena conciencia de sí y constituir, como objeto de ciencia, la serie de situaciones móviles que tan cuidadosa y empeñadamente había edificado" (Gómez, 1990:18).

En este punto, aun reconociendo el papel de estos factores, lo que prima en este cambio no es el objeto o el sujeto de conocimiento, lo que causa la variación sustancial es el método utilizado (aunque para ello necesite del contexto de una sociedad moderna). En nuestra opinión, aquí reside el carácter diferencial entre los llamados precursores y la Sociología moderna, en la aplicación del método científico moderno. Aunque como proceso histórico, la concreción del punto de inicio (el año cero) de la constitución del método se nos escapa y se convierte en una referencia simbólica más o menos artificial. Por esta razón, hay que ser flexibles en esta cuestión, relativizando en cierta medida sus límites. Retomamos aquí a R. Aron, quien confiesa que:

"Adopté una definición cuya imprecisión reconozco, sin creerla por ello arbitraria. La sociología es el estudio que se pretende científico de lo social como tal, sea en el nivel elemental de las relaciones interpersonales, o en el nivel macroscópico de los grandes conjuntos, las clases, las naciones, las civilizaciones o utilizando la expresión corriente, las sociedades globales. Esta definición nos permite comprender por qué es dificultoso escribir una historia de la sociología, y determinar dónde comienza y dónde concluye. Hay muchos modos de interpretar la intención científica o el objeto social. ¿La sociología exige simultáneamente esta intención y este objeto, o comienza su existencia cuando aparecen uno u otro de ambos caracteres?" (Aron, 1970:20).

Al hablar de una sociología que se "pretende científica", al apuntar cierto grado de incertidumbre basado en la libertad, al referirse a la existencia de distintos modos de interpretar la intención científica y el objeto social, R. Aron amplía el proceso paulatino y progresivo que culmina en el siglo XIX con la constitución de un conocimiento científico moderno. Reflexiona este autor que: "La sociología del siglo XIX señala indudablemente un momento de reflexión de los hombres acerca de sí mismos, el momento en que adquiere condición temática lo social como tal, con su carácter equívoco, unas veces relación elemental entre individuos y otras entidad global. Expresa también una intención que no es radicalmente nueva, sino original por su radicalidad, la de un conocimiento propiamente científico, de acuerdo con el modelo de las ciencias de la naturaleza, y persiguiendo un mismo objetivo: el conocimiento científico debería otorgar a los hombres el dominio de su sociedad o de su historia, del mismo modo que la física y las química les facilitaron el dominio de las fuerzas naturales" (Aron, 1970: 20).

Esta afirmación no resta importancia a los momentos anteriores de la sociología, pensamiento que suscribimos y que nos lleva a asumir que, así como existía ciencia antes de la Ciencia moderna, también se hacía sociología (llámese ésta como se quiera: precursora, presociología...) antes de la Sociología moderna. En resumen, sin poner en cuestión, en absoluto, la Sociología moderna (ni su método, ni su objeto, ni su sujeto de estudio, ni tan siquiera su historia), nos parece necesario hacer una pequeña pero imprescindible puntualización en la que apelamos a la perspectiva histórica para comprobar que no sólo la Sociología moderna es sociología.

\subsection{Los inicios de la Sociología española}

Tras la necesaria apreciación precedente, detenemos esa disertación aquí y volvemos la vista otra vez a nuestro particular objeto de estudio (y a su vez sujeto de conocimiento), R. de la Sagra. 
Dentro de las investigaciones que sobre la labor sociológica de nuestro autor se realizan, se han de tener en cuenta dos elementos de reflexión (que lamentablemente no siempre se dan de forma simultánea): el análisis de su obra de carácter sociológico y su situación en un determinado lugar en la historia de la disciplina. Al mismo tiempo, a la hora de situar la figura de R. de la Sagra en esta área de estudio, hay que tener en consideración cómo se ve a sí mismo y cómo es visto por los demás. Aquí nos centraremos, como hemos dicho, en la contextualización del autor en el momento inaugural de la Sociología española y en cómo es visto, dejando para otra ocasión la consideración de las características sociológicas de su obra.

Veamos primero el panorama general de los inicios de la Sociología española.

Revisando los estudios sobre el tema, a pesar de un amplio consenso sobre las figuras de finales del siglo XIX en España (sobre todo a partir de la primera cátedra de Sociología en 1898 en la Universidad Central, ocupada por Manuel Sales i Ferré), hay notorias diferencias en cuanto a la consideración de los autores anteriores, sobre algunos de los cuales existe una cierta resistencia a etiquetarlos cómo sociólogos. Si bien hay una general aceptación de ciertos nombres de finales del siglo XIX y principios del XX dentro de la disciplina, la línea de separación entre sociólogos y presociólogos varía según los autores, entre los que subsiste la disputa sobre a quién le pertenece el honor de ser el fundador de la Sociología española. Ofreceremos aquí una pequeña muestra de este debate.

La creación de la primera cátedra supone el reconocimiento oficial (institucional) de la materia, aunque su entrada efectiva en el mundo académico es anterior. M. Núñez Encabo afirma que: "A pesar de que a finales del siglo XIX en nuestro país la referencia a la Sociología era tema de moda en conferencias y publicaciones de todo tipo, faltaba, sin embargo, su inclusión en los planes de estudios universitarios. El reconocimiento del carácter científico de la Sociología sólo se alcanzará con su inclusión en los Planes de Estudio de la Universidad" (Núñez, 2000:31).

A. Posada también nos habla de las experiencias previas a la primera cátedra: "en cierta reforma, desgraciadamente fracasada, de la segunda enseñanza (1894) se creaba una cátedra de Sociología y ciencias éticas, y que en distintas ocasiones se ha propuesto la creación, en el doctorado de Derecho ó de Filosofía, de una cátedra de Sociología. Por otra parte, la más importante sociedad científica de España, el Ateneo de Madrid, ya en 1882 discutió en una de sus Secciones, durante todo un curso, los Fundamentos de la Sociología, y más recientemente, desde 1896-97, en la Escuela de altos estudios, organizada con auxilio oficial, en el mismo Ateneo de Madrid, se han dado varias enseñanzas sociológicas (...), la importancia de los estudios sociales ha sido consagrada de un modo casi oficial en la Universidad de Oviedo, mediante la creación, dentro de la Facultad de Derecho, de una Escuela práctica de estudios jurídicos y sociales (...), en la Institución libre de enseñanza de Madrid, la sociología forma parte del programa de educación general (primaria y secundaria)" (Posada, 1899:223).

Y esto sólo en lo que respecta al mundo académico, pues el interés por la sociología por parte de la prensa escrita y las revistas era ampliamente reconocido.

Todo esto confirma la existencia de un interés por la Sociología anterior a esta institucionalización, con profesores con programas y procedimientos influidos por su interés por esta ciencia, con una pluralidad de enfoques que supondrá una difusión asistemática e imprecisa de la Sociología. A pesar de su indefinición, estos esfuerzos más o menos aislados, más o menos constantes, terminan por promover un importante movimiento cultural y científico que recorrerá las últimas décadas del siglo XIX y que supondrá "el paso desde una metafísica idealista principalmente neoescolástica y krausista y en menor medida hegeliana, a 
una sociología positivista y agnóstica" (Núñez, 2000:13), cuyo culmen será la inclusión de la Sociología de una forma "oficial" en la vida universitaria a través de la constitución de la primera cátedra. Resulta curioso cómo, a pesar de establecer un corte nítido (pre-post institucionalización), esta postura reconoce la existencia de una tradición anterior, a la que, simultáneamente, otorga un papel fundamental al posibilitar la institucionalización y sitúa en una posición de inferioridad al no ser sociología institucionalizada. En este sentido, hemos de destacar cómo, desde esta posición, la versión institucionalista que se genera de la disciplina sirve para unificar las distintas opiniones, dando un referente formal, institucional y académico que, pese a su carácter restrictivo, puede ser compatible con las diferentes visiones del panorama sociológico.

M. Núñez Encabo, que menciona a J. Moreno Nieto como "uno de los que primero se refiere a la Sociología en un discurso pronunciado el 26 de noviembre de 1874 en la inauguración del Curso de la Academia de Jurisprudencia y Legislación de Madrid titulado La Sociología" (Núñez, 2000:17), dirá que "no puede negarse a Sales el título de fundador de la Sociología española." (Núñez, 2000:28), no tanto por su cátedra como por su obra. Para él, son los cuatro tomos del Tratado de sociología que M. Sales y Ferré comienza a publicar en 1889 los que constituyen la primera obra sociológica española de creación doctrinal y sistematización, siendo el primero que le da un carácter científico y autónomo, frente a la consideración filosófica que al respecto mantienen otras corrientes. Así, "Sales y Ferré se convierte, tanto por la naturaleza de su obra sociológica como por la fecha en que se produce en el primer sociólogo español y uno de los primeros europeos. En efecto los considerados padres fundadores de la Sociología, publican por esas mismas fechas sus primeras obras sociológicas (...)" (Núñez, 2000:29), exceptuando a A. Comte, que publica sus Cursos de Filosofía Positiva en el período 1830-1842 y H. Spencer que publica los Principios de Sociología en 1876.

L. Moreno sostiene que: "En la primera hornada de científicos sociales españoles y junto a Manuel Sales y Ferrè se debe incluir también al "protosociólogo" Jaime Balmes, así como a Gumersindo de Azcárate, Adolfo González Posada, considerado por muchos como el primer sociólogo (sic) "genuino" español, y a Severino de Aznar" (Moreno, 1990:71).

Por su parte, E. Gómez Arboleya considera que en la disciplina "Pueden ordenarse como figuras iniciales, F. Giner y Costa; de transición, G. Azcárate. Sociólogos en sentido propio, Sales y Ferré, A. Posada y S. Aznar" (Gómez, 1990:22).

F. Morente especifica que: "La estructura del "endogrupo" de la primera iniciativa sociológica forma la siguiente secuencia grupal según sus figuras más relevantes. Atendiendo a la cronología aparecerían en primer lugar las que se han dado en llamar las figuras iniciales: Francisco Giner y Joaquín Costa; las figuras de transición: Gumersindo Azcárate, Concepción Arenal, y los protosociólogos: Sales y Ferré, Adolfo G. Posada y Severino Aznar" (Morente, 2000:278-279).

En el caso de A. Perpiñá, "en su conocido texto de 1967, La sociología en España, apunta a Juan Donoso Cortés, Jaime Balmes, Concepción Arenal y Julián Sanz del Río como teóricos de una filosofía social precursora de la sociología" (Sarabia, 2001:19). Incluso hay quien prioriza el papel de una corriente filosófica concreta, el krausismo, en el inicio de la Sociología moderna, como es el caso de E. Lamo (1990), A. Perpiñá y D. Núñez (Sarabia, 2001).

No obstante, para algunos autores hay que esperar hasta principios del siglo XX para hablar de Sociología científica en España: "Pendant la première phase, jusqu'en 1918, nous ne trouvons pour ainsi dire que des « amateurs » de questions sociales, des hommes d'action 
plutôt que de pensée, des réformateurs des conditions sociales presque toujours confondues avec les problèmes du travail. La sociologie scientifique apparaît plus tard, dans la période qui commence avec la liquidation de la première guerre mondiale" (Mendizabal, 1947:658).

La causa de esto la sitúa A. Mendizabal en que, hasta entonces, los españoles tendían a la búsqueda del carácter normativo en las ciencias sociales, más que a la visión de la realidad que les proporcionaba la sociología, pues, el español, "Il aime savoir à quoi se conformer, savoir ce que «devrait être ». Ce qui «est» lui paraît sans importance" (Mendizabal, 1947:658), aunque, como podemos comprobar, para autores como R. de la Sagra, la búsqueda del "deber ser" no impide el conocimiento del ser.

Contrarrestando esta última opinión, nos gustaría mencionar aquí a J. Costa, quien se remonta más allá del siglo XIX, tomando el siglo XVI como punto de partida de los orígenes de la Sociología española: "La Sociología española, en cuanto se refiere al origen, fundamento y objeto de la sociedad humana, a su relación con la Naturaleza útil, que es decir, a su cimiento físico, a la solidaridad, necesaria o voluntaria, entre los asociados, a la dirección y gobierno de su actividad, a la conexión del organismo social con sus órganos y de los fines sociales entre sí, tiene su punto de arranque (y no podría haber ambicionado más ilustre ni más honrada una) en el libro De subventione Pauperum sive de Humanis necessitatibus libri II, con alguna parte del de Causis corruptarum artium, de Juan Luis Vives, y en el de Rege et Regis institutione del P. Mariana, estos dos grandes fundadores de la filosofía y de la historia en España. Ciertamente, ni la obra del inmortal polígrafo valentino ni la del egregio historiador y economista talaverano nos dan una concepción clara, acabada y sistemática ( Spencer, ni eran de esperar tales amplitudes ni tal método en siglo tan crítico y tan poco a propósito para síntesis y construcciones que no fueran de fantasía, como la de Tomás Moro; pero encierran intuiciones genialísimas, de que ellos mismos parecen asustarse, vislumbres y anticipaciones llenas de provechosa sugestión, y en todo caso exigencias, en que puede decirse que late el problema entero de la Sociología, planteado desde puntos de vista parciales y complementarios, ético y dinámico en aquél, mecánico y formal en éste" (Costa, 1983:104-105). E, incluso, J. Costa llega a remitir a una figura anterior de ese mismo siglo, el fraile Alonso de Castrillo.

A su vez, otros autores se apoyan en J. Costa y establecen a J. L. Vives como la primera figura a consignar en la Sociología española, destacando su papel como reformador social. Éste es el caso de H. E. Barnes y H. Becker, quienes también afirman que: "Antes de esta época hubo muchos pensadores sociales en España -entre ellos, San Isidoro de Sevilla con sus teorías sobre el origen de la sociedad y del estado natural del hombre- pero los teóricos del siglo XVI superaron en mucho a sus predecesores. Testimonio de ello es la audacia intelectual del erudito Juan Luis Vives (1492-1540) que mucho antes de Francisco Bacon (1561-1626) declaró que la observación de la naturaleza, más bien que la lectura de Aristóteles y de los Padres, es el camino del saber" (Barnes et al., 1984:298).

De J. L. Vives, destacan su libro sobre la asistencia a los pobres, De subventione pauperum sive de humanis necessitatibus (1526), y su pensamiento de que "es mucho más importante que el magistrado dedique su energía a la producción de buenos ciudadanos que no al castigo y represión de los malhechores. Porque ¡cuánto menos habría que castigar, si estas cuestiones fueran consideradas rectamente de antemano!” (Barnes et al., 1984:298), además de prestar atención al carácter moral de las formas de auxilio y la enseñanza especial de los ciegos. El siguiente nombre que mencionan estos autores es el de Francisco de Vitoria.

También A. Posada rememora la postura de J. Costa, considerando que "Los estudios sociales, si no en el sentido positivo, realista y objetivo con que suelen hacerse hoy los que 
constituyen la literatura sociológica, a lo menos con un sentido tendencioso de crítica de la condición humana, de reforma de la vida económica, tienen en España antiguo y noble abolengo.” (Posada, 1899:214), incluyendo a J. Huarte de San Juan, J. L. Vives, J. de Mariana o B. J. Feijóo, aunque como antecedentes, pues al referirse a "sociólogos españoles" en el citado texto considera ya como auténticos sociólogos a Joaquín Costa, Francisco Giner de los Ríos, Gumersindo de Azcárate y Manuel Sales y Ferré (Sarabia, 2001). Asimismo, M. Núñez Encabo sitúa a F. Suárez, J. de Mariana, J. L. Vives, Castrillo, F. Martínez Marina como precursores más o menos indirectos de la Sociología española, e incluso comenta la existencia de una serie de iniciadores más cercanos en el tiempo, pero que provienen de otro tipo de estudios y sin embargo realizan aportaciones a la disciplina como J. Costa, P. Dorado Montero y V. Santamaría de Paredes (Núñez, 2000).

Un elemento que hemos de destacar y del que ya hemos hablado antes, es que, tanto J. Costa, como A. Posada, H. E. Barnes y H. Becker, llaman la atención sobre cómo el descubrimiento y conquista de América generaron indagaciones sobre la condición social de los indígenas y una investigación sobre la organización de las sociedades: "los historiadores y geógrafos se ocuparon de la vida de los indígenas y de las tierras que ocuparon; las obras de Bernal Díaz del Castillo, Zárate, Cabeza de Vaca, Castellanos y muchos otros sabios suministraron una información que hubiera podido ser empleada para crear, con carácter de ciencias, la etnografía y geografía humana española, anticipándose mucho a todos los competidores de otras naciones. Sin embargo, no se continuó la obra de los primeros exploradores y ha quedado para los sabios de las repúblicas latino-americanas la empresa de emular a sus grandes predecesores" (Barnes et al., 1984:301).

El eclecticismo y singularidad de estas aportaciones del pensamiento sociológico español, que participan en la corriente de los estudios sociales europeos de su tiempo, hace que algunos autores lo consideren como un esfuerzo aislado y de limitado alcance, necesitado de su institucionalización o de la poderosa guía del krausismo para orientarlo y conducirlo hacia su sistematización -una condición que dará su carácter a la Sociología española- (Posada, 1899). Reiteramos aquí la visión de la sociología como proceso dialéctico, como dice F. Morente: "Nuestra interpretación de las fuentes relacionadas con la emergencia de la Sociología entiende que dicha historia no es evolucionista, sino que más bien es una historia fundada sobre procesos discontinuos e internamente dialécticos que promueven no obstante un cúmulo de actividad que desemboca finalmente en la institucionalización de la sociología española (si así cabe llamarla), historia promovida por un incipiente endogrupo "pro" sociológico" (Morente, 2000:277).

De esta manera, se han de tener siempre presentes los antecedentes que sientan las bases de lo que vendrá después. Y lo que vendrá después es que, a estos precedentes, se le unirá el desarrollo alcanzado por la Economía política y social en nuestro país, el avance del Positivismo con su organicismo, las aportaciones del krausismo (receptor principal de este Positivismo al que añade matices metafísicos y filosóficos) y de los estudios antropológicos (especialmente de Antropología social, puente para llegar a la Sociología). Tampoco podemos olvidar la existencia simultánea de la perspectiva del catolicismo social (en la que se incluye a J. Balmes, J. Donoso y, en ocasiones, a Ramón de la Sagra, gracias a los contenidos de su último período), en menor medida, de corrientes positivistas, historicistas, hegelianas y neokantianas (Núñez, 2000). 


\subsection{Ramón de la Sagra en la historia de la disciplina}

Veamos ahora, cómo se refleja R. de la Sagra en los ojos de los otros, cómo califican a nuestro protagonista varios estudiosos de su obra provenientes de diversos campos (una pequeña muestra, pero significativa). Nuestro protagonista recibe numerosos epítetos elogiosos (lo que hace más extraña su condición de figura olvidada) por parte de numerosos autores. Entre su denominación como pensador social, presociólogo, iniciador de la sociología moderna o sociólogo, distan sutiles apreciaciones fundamentadas en su inclusión en el pensamiento español, el conocimiento que cada autor tiene de su figura y el concepto que se tiene sobre la sociología. Pero dejemos hablar a los expertos...

E. Gómez Arboleya llama la atención sobre R. de la Sagra: "De hecho, en las ciencias sociales pueden destacarse, en la primera mitad del siglo, dos figuras que merecen la más alta estimación: Ramón de la Sagra y Jaime Balmes" (Gómez, 1990:20). Más específicamente, A. Posada (como también lo hace J. Costa (1983)) sitúa a R. de la Sagra dentro de los autores economistas, concretamente, dentro de la escuela católica, corriente amplia, poco merecedora de ese nombre, que incluye desde posturas individualistas a socialistas (Posada, 1899). Estos autores economistas tienen amplios ecos sociológicos, de hecho, se señala el desarrollo alcanzado en España por la Economía política como una de las grandes influencias que tendrá la Sociología española. Por su parte, S. Cabeza León, comenta que R. de la Sagra es "a quien Azorín considera como uno de los precursores del insigne Costa, como un "presociólogo", estimando de modernísima, alguna de las aspiraciones que a mediados del siglo XIX acogía ya nuestro compatriota" (Cabeza, 1919:7). También aparece entre los precursores según E. Lamo: "E incluso antes de la Restauración podría hablarse de una etapa pre-sociológica del pensamiento español en la obra de Jaime Balmes, Ramón de la Sagra (saint-simoniano y colaborador de Proudhon) o Ildefonso Cerdá (seguidor de la Le Play)" (Lamo, 1992:120). M. Núñez Encabo, considerándole entre los antecedentes importantes, pero de menor influencia, en el nacimiento de la Sociología como ciencia en España, opina que tanto R. de la Sagra como J. Balmes "Pertenecen a una etapa previa al tratamiento de la Sociología como ciencia (Presociología)" (Núñez, 2000:16-17).

Entre los que distinguen en él una personalidad plenamente sociológica destacan R. Carballal Pernas, que estima a Ramón de la Sagra como "biólogo, estudante de Mediciña, filósofo, economista, político, sociólogo e penitenciarista, que de todas estas Cencias foi procramado mestre no seu tempo (...)" (Carballal, 1976:12); M. Rodríguez Caamaño, quien subraya su condición de "notable y adelantado representante del panorama sociológico español (...) digno y brillante pionero del pensar y el hacer sociológico en la España del siglo XIX” (Rodríguez, 1999:261); L. Legaz y Lacambra, que señala a R. de la Sagra como poseedor de "una visión y un pensamiento que, desde nuestra perspectiva, aparecen perfectamente encajados en el sistema de la Sociología clásica de la que el olvidado coruñés fué el más egregio representante en España" (Legaz, 1946:182); M. Casás, apuntando la modernidad del personaje: "Pero sí destacaremos, principalmente la nota característica de haber sido un precursor de la moderna sociología; y en un tiempo en que la Economía Política respondía a un criterio individualista preocupóse La Sagra de dar a esta ciencia un contenido y una tendencia sociales, con vislumbres claros de los más palpitantes problemas que hoy preocupan a los estadistas y sociólogos" (Casás, 1928,10) e incluso tildando a R. de la Sagra de "insigne sociólogo" (Casás, 1945:5); asimismo, un temprano D. Pazos remarca su carácter sociológico cuando dice: "Estaba por entonces la sociología en sus albores, confundida especialmente con la ciencia económica, con todo, resplandece en sus trabajos una elevación en el modo de tratar y considerar todos los temas, nacida sin duda de la amplitud y profundidad de sus conocimientos, aportaba para su dilucidación tal multiplicidad 
de datos, que por lo menos ha de contarse entre los precursores de esta ciencia. Sus lecciones de economía social, más que otra cosa pudieran titularse de Sociología. No se concretaba á estudiar los principios y los hechos sociales, bajo el aspecto solamente económico sinó que también los examinaba bajo el jurídico, el moral etc., etc. Así lo confirma en su "Ciencia social"' (Pazos, 1891); y L. Saavedra le otorga un protagonismo especial, al afirmar que, "Tras haber visto los antecedentes, podemos decir que, hablando con propiedad, Ramón De La Sagra es el primer sociólogo español. Nacido en La Coruña en 1798, es hombre de personalidad contradictoria y formación autodidacta, escribe una obra amplia y variada en la que, además de destacar una cultura vastísima, sobresale el empeño decidido en introducir el análisis sociológico como punto de referencia esencial en al (sic) contemplación de la sociedad humana" (Saavedra, 1991:35).

Pero, ¿qué opina de esto el propio Ramón de la Sagra? Él mismo considera que hace Sociología. En su interés por las ciencias sociales llega un momento en que él mismo es consciente (y así lo expresa) de que realiza un análisis social, de que puede integrarse en esa nueva "ciencia francesa" llamada Sociología. Y, por ello, explicita esta condición de sociólogo denominándose así en algunas de sus obras. El propio autor es consciente de realizar una labor sociológica (de ser sociólogo y de hacer sociología).

\section{CONCLUSIÓN}

Como hemos tenido ocasión de comprobar, la búsqueda de identidad de la Sociología es un proceso complejo en el que no sólo se produce una diferenciación con otras áreas de pensamiento, sino también una disparidad de posicionamientos internos, una diferenciación interna (Pino, 1990). En este artículo hemos intentado ofrecer una muestra de las distintas ópticas que afrontan el examen del arranque de la disciplina, subrayando la dificultad que entraña el abarcar tan delicada cuestión de una forma panorámica.

Al fin y al cabo, esta diversidad dentro de la unidad de la que hablamos no deja de ser un ejemplo de la plasticidad que permite esta materia y de la influencia que en su estudio tienen los propios analistas. Son estos unos elementos característicos que no hacen sino ahondar en la fragilidad del concepto "Sociología", que se ve abocado a una búsqueda constante de precisión a la hora de su estudio.

Esto se vuelve fundamental al abordar el análisis de su periodo inicial. El cuándo comienza y el quién inaugura este área de estudio (ya sea a nivel mundial o nacional) se convierten en cuestiones trascendentales que no resultan tan evidentes como se pudiera suponer en un principio. Y es en este momento germinal de la Sociología donde detenemos en esta ocasión nuestra mirada para centrarnos en una figura en particular, la de Ramón de la Sagra.

Así, con el recorrido histórico y bibliográfico que estamos a punto de finalizar, hemos intentado insertar a este autor español en su época a través de los ojos de los historiadores de la Sociología, ofreciendo un contexto en el que situarlo para poder comprender mejor la importancia de sus aportaciones, tratando de mitigar el desconocimiento del que es objeto. De esta forma, teniendo en cuenta el contexto y algunas de las opiniones citadas, si seguimos una política restrictiva en cuanto a la clasificación de los autores, podemos referirnos a R. de la Sagra como un presociólogo o precursor de la Sociología en sentido estricto. Sin embargo, opiniones que abogan por miras más amplias le consideran como un iniciador de la 
Sociología en el sentido moderno del término. Para poder situarlo con precisión, conviene profundizar en el análisis de su obra, tarea que recomendamos y emplazamos a realizar.

\section{BIBLIOGRAFÍA}

ÁLVAREZ-URÍA, F. y VARELA, J. (2000). La galaxia sociológica. Madrid: La Piqueta. ARON, R. (1970). Las Etapas del Pensamiento Sociológico. Buenos Aires: Siglo Veinte.

BARNES, H. E. y BECKER, H. (1984). Historia del pensamiento social. Corrientes sociológicas en los diversos países, vol. II. México: F.C.E.

CABEZA DE LEÓN, S. (1919). La Universidad de Santiago y Don Ramón de la Sagra. Notas históricas. Santiago: José $\mathrm{M}^{\mathrm{a}}$ Paredes.

CARBALLAL PERNAS, R. (1976). Ideario político-social y penitenciario de don Ramón de la Sagra. A Coruña: Academia Gallega de Jurisprudencia y Legislación.

CASÁS FERNÁNDEZ, M. (1928). "Don Ramón de la Sagra y la isla de Cuba". Eco de Galicia, 329, Habana, 10 febrero.

- (1945). Un gallego ilustre, don Ramón de la Sagra. A Coruña: Roel.

COSTA, J. (1983). Colectivismo Agrario en España, tomo I. Zaragoza: Instituto de Estudios Agrarios, Pesqueros y Alimentarios, Guara Editorial.

DE MIGUEL, A. (1972). Sociología o subversión. Barcelona: Plaza y Janés.

GINER, S. (2004). Teoría Sociológica Clásica. Barcelona: Ariel.

GÓMEZ ARBOLEYA, E. (1990). "Sociología en España". En S. Giner y L. Moreno (comp.). Sociología en España. Madrid: CSIC, pp. 17-50.

LAMO DE ESPINOSA, E. (1990). “Teoría Sociológica”. En S. Giner y L. Moreno (comp.). Sociología en España. Madrid: CSIC, pp. 345-352.

- (1992): “La sociología española desde 1939”. En R. Reyes (ed.). Las ciencias sociales en España. Historia inmediata, crítica y perspectivas. Madrid: UCM y Caja de ahorros y monte de piedad de Madrid, pp. 119-130.

LEGAZ y LACAMBRA, L. (1946). "Ramón de la Sagra, Sociólogo Español”. Revista Internacional de Sociología. 13: 155-182.

MENDIZABAL, A. (1947). "La Sociologie espagnole”. En G. Gurvitch y W.E. Moore. La Sociologie au XX siècle, vol. II. Paris: P.U.F, pp. 658-673.

MORENO, L. (1990). "La sociología en la España finisecular". En S. Giner y L. Moreno (comp.) Sociología en España. Madrid: CSIC, pp. 71-96.

MORENTE MEJIAS, F. (2000). "Sociología en España. Una aproximación sintética", Revista de Estudios Políticos. 108: 271-292.

MUCCHIELLI, L. (2000). "El nacimiento de la sociología en la universidad francesa (1880-1914)". En S. del Campo (coord.) La Institucionalización de la Sociología (1870-1914). Madrid: Centro de Investigaciones Sociológicas, pp. 41-60.

NÚÑEZ ENCABO, M. (2000). "Sales y Ferré y la primera institucionalización de la Sociología en España”. En S. del Campo (coord.) La Institucionalización de la Sociología (1870-1914). Madrid: Centro de Investigaciones Sociológicas, pp. 13-40.

PAZOS y GARCÍA, D. (1891). “Apuntes biográfico-bibliográficos del ilustre corunés Don Ramón de la Sagra”. Gaceta de Galicia. 286.

PINO ARTACHO, J. del (1990). La teoría sociológica. Un marco de referencia analítico de la modernidad. Madrid: Tecnos.

POSADA, A. (1899). "Los estudios sociológicos en España". En Boletín de la Institución Libre de Enseñanza. Madrid: Imprenta de Enrique Rojas, pp. 214-224 y pp. 246-256.

RIBES LEIVA, A. J. (2005). El "enfoque sociológico" en la producción intelectual de Francisco Ayala: una sociología de la sociología (Tesis inédita de doctorado). UCM, Madrid.

RODRÍGUEZ CAAMAÑO, M. J. (1999). "Ramón de la Sagra, pionero de la Sociología en España". Revista Española de Investigaciones Sociológicas. 88: 261-271. 
SAAVEDRA, L. (1991). El pensamiento sociológico español. Madrid: Taurus.

SARABIA HEYDRICH, B. (2001). "Precursores de la Sociología española. Siglo XIX". En S. del Campo (dir.) Historia de la Sociología española. Barcelona: Ed. Ariel, pp. 17-40.

SOTELO, I. (1973). "Sobre la institucionalización de la sociología en España". Sistema. Revista de Ciencias Sociales. 3: 59-76.

\section{Breve currículo:}

\section{Carmen Rodríguez Rodríguez}

Actualmente profesora en la Universidad de A Coruña y profesora-tutora de la UNED. Doctora en Sociología por la UCM con la tesis titulada Ramón de la Sagra. El diario de viaje como forma de conocimiento sociológico. Ha disfrutado de estancias en Santiago de Compostela y en París, y es autora de diversas publicaciones. Miembro del grupo de investigación Sociología en lengua castellana: Perspectiva histórica, centra su interés en la Sociología española, la Teoría sociológica y la Sociología de la cultura y de la comunicación. 